\title{
CONCEPTO Y NATURALEZA DE LAS SANCIONES ADMINISTRATIVAS EN LA DOCTRINA Y JURISPRUDENCIA CHILENA*
}

\section{EDUARDO CORDERO QUINZACARA**}

RESUMEN: Esta investigación tiene por objeto establecer el concepto de sanción administrativa que sigue nuestra doctrina y jurisprudencia nacional. Para tal efecto, el autor analiza la distinción que existe entre estas sanciones, los actos administrativos desfavorables y las penas, y la forma como la doctrina y la jurisprudencia lo ha interpretado. En definitiva, se sostiene que la sanción administrativa es una especie de acto administrativo desfavorable, aunque sujeto a una serie de garantías en su aplicación, identificándose ontológicamente con las penas, en el marco de una política represiva que delimita el legislador dentro de los límites sustantivos que consagra nuestra Constitución.

PALABRAS CLAVE: Sanción administrativa - Actos administrativos desfavorables - Pena.

\section{CONCEPT AND NATURE OF ADMINISTRATIVE SANCTIONS IN THE CHILEAN DOCTRINE AND JURISPRUDENCE}

ABSTRACT: This research aims to establish the concept of administrative sanction according to the Chilean doctrine and jurisprudence. To achieve that, the author discusses the differences between those sanctions, the unfavorable administrative acts and criminal penalties, and the way how the doctrine and jurisprudence have interpreted it. It is argued that the administrative sanction is a type of unfavorable administrative act, but liable to several guarantees in its execution, ontologically identified

Fecha de recepción: 11 de marzo de 2012.

Fecha de aprobación: 18 de enero de 2013.

** Abogado, Doctor en Derecho, Profesor de Derecho administrativo de la Pontificia Universidad Católica de Valparaíso, Chile. Correo electrónico: eduardo.cordero@ucv.cl. Este trabajo es parte de una investigación financiada por FONDECYT referida al proyecto "Fundamentos y principios de la potestad sancionadora de la Administración del Estado en el Derecho chileno" No1110791. 
with the penalties as part of a repressive policy that defines the legislator within the limits that are set forth in our Constitution.

KEY WORDS: administrative sanctions - unfavorable administrative acts - penalty

Sumario: 1) Antecedentes generales. 2) Infracciones y sanciones administrativas. 3) La delimitación de las sanciones administrativas. (3.1) Actos con efectos desfavorables y sanciones administrativas. (3.1.1) La perspectiva doctrinal. (3.1.2) La jurisprudencia constitucional. (3.1.3) La jurisprudencia administrativa. (3.1.4) La jurisprudencia judicial. (3.2) Las Sanciones Administrativas y las Penas. (3.2.1) Aspectos generales. (3.2.2) La discusión en la doctrina nacional. (3.2.3) La jurisprudencia constitucional. (3.2.4) La jurisprudencia administrativa. (3.2.5) La jurisprudencia judicial. 4) Conclusiones. 5) Bibliografía.

\section{1) ANTECEDENTES GENERALES}

El tema de las infracciones y sanciones administrativas es una materia que plantea un sinnúmero de paradojas y problemas, siendo al mismo tiempo de una importancia práctica notable, producto de su crecimiento exponencial en el marco de una mayor intervención del Estado para regular y controlar un conjunto ingente de conductas que cada vez generan un mayor riesgo a diversos bienes jurídicos. En este sentido, nuestro legislador aspira a encontrar en manos de la Administración del Estado una actuación que puede ser más oportuna y eficaz para disciplinar dichos comportamientos, reservando a la actuación de los Tribunales de Justicia la represión de hechos de mayor gravedad, respetando el carácter subsidiario y de última ratio que se reconoce al Derecho penal.

En este sentido, constituye un dato positivo innegable la existencia de una abundante legislación que entrega a los órganos de la Administración del Estado poderes punitivos que regulan determinados sectores de la vida social, dada la necesidad de resguardar un cierto orden o bienes jurídicos, que van desde el ámbito sanitario, urbanístico, ambiental, tributario, aduanero, mercado de valores, etc. Así las cosas, cada vez se encuentra más lejos la materialización del ideario revolucionario liberal de reservar el ejercicio de los poderes punitivos del Estado en manos de los órganos jurisdiccionales, para superar el denominado Derecho penal prebeccariano, entregado a órganos de naturaleza administrativa, sin consideración de principios y garantías de ningún tipo.

En efecto, bajo esta forma de ejercicio de los poderes punitivos del Estado no solo se conserva un resabio del absolutismo, sino que -tal 
como lo hemos señalado- cada vez más se otorgan dichos poderes a órganos administrativos, cuyo fundamento se encontraría en una forma más eficiente y oportuna para reprimir determinadas conductas de menor gravedad y que, por tanto, no demandaban de mayores garantías sustantivas y procesales en su aplicación. Sin embargo, la idea de facilitar una intervención punitiva estatal con garantías mínimas, lleva lentamente a la tentación de agravar estas sanciones generando una asimetría con aquellas contenidas en la legislación penal, al punto de resultar, en muchos casos, más intensas y graves que la aplicada por los tribunales de justicia.

Por tal razón, el tema ha pasado de ser una cuestión meramente secundaria, inherente a la singularidad, contingencia y burocracia que es propia de la Administración, transformándose en un asunto capital que le da sentido y fundamento a la actuación del Estado frente a la sociedad, especialmente para garantizar la protección de determinados valores y bienes constitucionales. En este contexto, la potestad punitiva en manos de la Administración se ha transformado en un importante instrumento de intervención y de mecanismo en la conformación de la sociedad sobre las premisas constitucionales de promoción del bien común y de integración armónica de todos los sectores de la nación. Esto explica que su crecimiento no se deba a una contingencia histórica "tolerada" constitucionalmente, sino que responda a una exigencia constitucional cuyo fundamento, sentido y función demanda de un necesario análisis dogmático a la luz de nuestro ordenamiento jurídico.

Ahora bien, el estudio de esta materia debe partir necesariamente por una definición del concepto de infracción administrativa, que permita establecer su naturaleza jurídica y, a partir del mismo, determinar sus fundamentos en el orden constitucional. Esto permitirá, además, establecer el conjunto de principios a los cuales se encuentra sometida desde el punto de vista sustantivo y procedimental. El primero de estos puntos será el objeto de este trabajo, teniendo presente dos aspectos: a) El tema de la naturaleza de las infracciones administrativa y su consecuencia jurídica, esto es, las sanciones administrativa, es un tópico de antigua data, especialmente en los estudios jurídico-penales ${ }^{1}$. En este caso, nuestro análisis

1 Una obra clásica sobre esta materia y que es de referencia obligada es la de Goldschmidt, James (1969) Das Verwaltungsstrafrecht. Eine Untersuchung der Grenzgebiete zwischen Strafrecht und Verwaltungsrecht auf rechtsgeschichtlicher und rechtsvergleichender Grundlage. Aalen: Scientia Verlag, 603 p., que es una reimpresión de la edición publicada en Berlín por C. Heymann en 1902. También se puede consultar en GoldschmidT, James (2010). "Concepto y cometido del Derecho penal administrativo". En Goldschmidt, James: Derecho, derecho penal y proceso. T. I. Problemas fundamentales del Derecho. Madrid: Marcial Pons, pp. 291-318. Una relación sobre los problemas que plantea esta materia se pueden ver en Cury, Enrique (2005) Derecho Penal. Parte General. 8a edición. Santiago de Chile: Universidad Católica de Chile, pp. 100 y ss. y Rodríguez, Luis (1987). "Bases para distinguir entre infracciones criminales y administrativas". Revista de Derecho de la Pontificia Universidad Católica de Valparaíso, XI, pp. 117-163. 
dará cuenta de la forma como ha sido enfrentado el problema por parte de la doctrina y jurisprudencia nacional reciente, especialmente con el objeto de establecer el concepto subyacente que sirve de base a dichos estudios; y b) Este estudio no tiene por objeto establecer lo principios a los cuales se encuentran sometidas estas infracciones administrativas. Si bien se hará alguna mención de los mismos, su desarrollo y análisis detenido tendrá lugar en un trabajo posterior.

\section{2) INFRACCIONES Y SANCIONES ADMINISTRATIVAS}

En el último tiempo, el tema del poder punitivo de la Administración se ha estudiado en el marco de las "sanciones administrativas" o del "Derecho administrativo sancionador", quedando en un segundo plano la conducta ilícita que se sanciona, en este caso la infracción administrativa. Por su parte, durante el siglo XIX esta materia fue analizada por la doctrina alemana dentro del "Derecho penal de policía", teoría que fue sustituida a comienzos del siglo XX por la del "Derecho penal administrativo". Esta última denominación evoca mucho mejor la distinción tradicional que se hace en el Derecho penal entre delito, por una parte, y la pena, por la otra, asociada al concepto de responsabilidad criminal.

Ahora bien, la doctrina penal nacional ha tenido el cuidado de hacer la distinción y abordar el tema desde la perspectiva de las infracciones administrativas ${ }^{2}$, aunque también se ha estudiado esta materia bajo la distinción entre pena penal y pena administrativa ${ }^{3}$. Por su parte, la doctrina administrativa la ha analizado bajo el rótulo de sanciones administrativas, enmarcado dentro de la actividad de policía o de ordenación que realizan los órganos administrativos, siguiendo especialmente a la doctrina española. ${ }^{4}$

Si bien ambas categorías están estrechamente implicadas, resulta capital hacer la distinción, en la medida que la sanción administrativa no es sino un tipo de responsabilidad que surge de la comisión de un ilícito o infracción administrativa. De esta forma, si se conforman o reúnen los elementos que configuran dicha infracción, necesariamente se debe imputar al autor de dicho acto las consecuencias negativas o la responsabilidad que deriva de la misma: la sanción administrativa. En ambos casos, esto es, en la determinación del hecho constitutivo de la infracción y en la aplicación de la sanción, le corresponde intervenir a un órgano que forma

RodríGUez (1987) 117-163.

Cury (2005) 100 y ss.

Por todos, véase García de Enterría, Eduardo y Fernández, Tomás-Ramón (1999) Curso de Derecho Administrativo. T. II, $11^{\text {a }}$ edición. Madrid: Thomson, 754 pp., p. 163 y ss., y Garrido Falla, Fernando (2002) Tratado de Derecho Administrativo. 11 a edición, Vol. II. Madrid: Tecnos. 
parte de la Administración del Estado, previamente facultado por el ordenamiento jurídico a través de la atribución de una potestad expresa.

Sin embargo, se encuentra tan asentado en nuestra doctrina y jurisprudencia la expresión "sanciones administrativas", que utilizaremos de forma indistinta la referencia a esta materia como poder punitivo de la Administración, infracciones administrativas y, por supuesto, sanciones administrativas, todo lo cual aparece -por lo demás- en una secuencia lógica natural: el legislador tipifica la infracción, establece la sanción y atribuye a la Administración la potestad de aplicarla.

\section{3) LA DELIMITACIÓN DE LAS SANCIONES ADMINISTRATIVAS}

Existe una relación directamente proporcional entre la gravedad de las medidas que adopta el Estado y que afectan la esfera jurídica de los particulares, y el estatuto de garantías al cual se encuentran sometidas. Así, es de toda lógica que el régimen sancionador penal, más enérgico y grave en las sanciones que se adoptan, esté sujeto a una serie de formas y ritualidades que hacen más estricto el ejercicio de esta forma de potestad punitiva. En el escalón siguiente se encuentran las sanciones que aplica la propia Administración, sujetas a un sistema de principios y garantías más atenuados o "matizados" que se debe respetar en el respectivo procedimiento administrativo sancionador. Por último, existen una serie de actos desfavorables que emanan de los órganos de la Administración del Estado, pero que no constituyen sanción en sentido estricto.

Este sistema escalonado que asocia la gravedad de las consecuencia jurídica respecto de los procedimientos y garantías que se van a seguir para hacerlas efectivas, es lo que ha obligado a deslindar cada uno de estos niveles. A su vez, siguiendo este camino se ha podido ir delineando por la doctrina un concepto de sanción administrativa, que las separa de las penas penales y de los actos desfavorables que emanan de la propia Administración. Analizaremos cada uno de estos puntos.

Por lo tanto, en este apartado nos preocuparemos de distinguir entre la sanción administrativa y los actos administrativos con efectos desfavorables (3.1), para luego establecer la separación entre sanción administrativa y sanción penal (3.2).

\section{1) ACTOS CON EFECTOS DESFAVORABLES Y SANCIONES ADMINIS- TRATIVAS}

\subsection{1) La perspectiva doctrinal}

En el ejercicio de las funciones que le son propias, la Administración puede adoptar una serie de actos que afectan la esfera jurídica de los par- 
ticulares, sin que todos ellos sean necesariamente expresión de un poder punitivo o sancionador. Así, puede ordenar el traslado de un funcionario, cerrar un establecimiento por no contar con permiso sanitario, suspender un concurso público, etc. Para la doctrina, la distinción entre los actos desfavorables en general y las sanciones viene dado por dos elementos centrales: a) la sanción administrativa es consecuencia de una conducta ilícita o infracción; y b) la sanción administrativa tiene una finalidad esencialmente represiva o de castigo. De esta forma, la sanción administrativa es un acto desfavorable que afecta la esfera jurídica de un particular con una finalidad represora frente a una infracción o conducta ilícita.

En general, nuestra doctrina no entrega un concepto preciso de sanción administrativa. Algunos dan por supuesto el concepto, asimilando derechamente a la sanción penal ${ }^{5}$, mientras otros utilizan un concepto bastante amplio ${ }^{6}$. Sin embargo, en el último tiempo algunos autores se han cuidado de entregarnos un concepto más preciso y técnico de sanción administrativa. Así, Jorge Bermúdez distingue entre una noción amplia de sanción, como "toda aquella retribución negativa dispuesta por el ordenamiento jurídico como consecuencia de la realización de una conducta”, mientras que la noción estricta de sanción administrativa sería "aquellas retribuciones negativas previstas como tales en el ordenamiento jurídico como consecuencia de una infracción administrativa". De esta forma, no toda consecuencia gravosa derivada de una vulneración del ordenamiento jurídico es sanción strictu sensu ${ }^{7}$.

Este criterio de distinción reconoce una clara influencia de la doctrina y jurisprudencia española. Así, por lo demás, da cuenta uno de los juristas más importantes de España, al señalar que la sanción administrativa es "un mal infligido por la Administración a un administrado como consecuencia de una conducta ilegal" 8 . Por su parte, el Tribunal Constitucional Espańol ha ratificado en diversas sentencias este criterio, especialmente para descartar la posibilidad de obtener la aplicación de las garan-

5 Véase Soтo Kloss, Eduardo (1979/1980). “Derecho Administrativo Penal. Notas para el estudio de la potestad sancionadora de la Administración”. Boletín de Investigaciones Facultad de Derecho de la Pontificia Universidad Católica de Chile, No 44-45, pp. 95-103, y Sото KLoss, Eduardo (2005) "La potestad sancionadora de la Administración, ¿se adecua a la Constitución?”. En $A A . V V$. Sanciones Administrativas y Derechos fundamentales: regulación y nuevo intervencionismo. Santiago de Chile: Universidad Santo Tomás, pp. 29-49. En el mismo sentido, Aróstica, Iván (1987). "Algunos problemas del Derecho Administrativo Penal”. Revista de Derecho Universidad de Concepción, No 182, 1987, pp. 71-81.

6 Camacho Cépeda, Gladys (2010) Tratado de Derecho Administrativo. La actividad sustancial de la Administración del Estado. Santiago de Chile: Abeledo Perrot, 457 pp., pp. 207-209.

7 Bermúdez, Jorge (1998). "Elementos para definir las sanciones administrativas". Revista Chilena de Derecho, Número Especial, pp. 324-325. García de Enterría/Fernández (1999) 163. 
tías constitucionales propias de estas sanciones 9 . Por lo tanto, tal como lo señala Santamaría Pastor, la sanción administrativa se caracteriza, frente a los restantes actos de contenido desfavorable, por su carácter reaccional respecto de una conducta ilícita ${ }^{10}$.

El concepto así delineado ha permitido a la doctrina y jurisprudencia espańola descartar una serie de actos de la Administración que, a pesar de su contenido desfavorable, no constituyen sanción en sentido estricto:

- Todo acto que no sea consecuencia de una conducta ilícita, como la expropiación de un inmueble, la suspensión de un concurso público, la extinción de un acto administrativo por caducidad o cumplimiento del plazo, etc.

- Aquellos actos que sean consecuencia de una conducta ilícita, pero que no tienen una finalidad represiva o reaccional, como las medidas de restablecimiento del orden alteradas por dicha conducta (vgr. la suspensión de una construcción por no tener permiso de edificación, el cierre de un local comercial sin permiso municipal, etc.) o medidas de reparación o resarcimiento (vgr. la reparación del perjuicio causado al patrimonio público o la restitución de los gastos asumidos por la Administración en los casos de ejecución por la vía sustitutoria).

Ahora bien, como lo hemos señalado, salvo en el trabajo de BERMúDEZ, nuestra doctrina en general ha preterido cualquier mención al concepto de sanción administrativa ${ }^{11}$, salvo aquellos que las identifican con las sanciones penales ${ }^{12}$.

9 Así, en Sentencia del Tribunal Constitucional Español No42/1989, de 16 de febrero sostuvo que "[...] las garantías del artículo 24 CE (...) no pueden trasladarse sin más a las actuaciones administrativas, salvo que estas tengan una naturaleza sancionadora equivalente materialmente a las actuaciones penales”. En STCE 47/2001, de 15 de febrero, señala que "[...] ya hemos advertido en distintas ocasiones que las garantías recogidas en el artículo 25 CE únicamente resultan aplicables a medidas que responden verdaderamente al ejercicio del ius puniendi del Estado o tienen un verdadero sentido sancionador". Por último, en STCE $331 / 2006$, de 20 de noviembre, afirma que "en distintas ocasiones hemos advertido sobre la improcedencia de extender indebidamente el concepto de sanción, con la finalidad de obtener la aplicación a las garantías constitucionales propias de este campo, a medidas que no responden verdaderamente al ejercicio del ius puniendi del Estado".

10 Santamaría Pastor, Juan Alfonso (2009) Principios de Derecho Administrativo. T. II, $2^{\text {a }}$ edición. Madrid: Iustel, p. 388.

11 Vergara, Alejandro (2004). "Esquema de los principios del Derecho Administrativo Sancionador". Revista de Derecho Universidad Católica del Norte, ańo 11, No 2, pp. 137-147; y Román Cordero, Cristian (2008). "Derecho Administrativo Sancionador: ¿Ser o no ser? He aquí el dilema”. En Pantoja, Rolando (coordinador): Derecho Administrativo. 120 años de Cátedra. Santiago de Chile: Editorial Jurídica de Chile, pp. 107-141, 441 pp.

12 Soto Kloss (nota 5) y Aróstica (nota 5). También se puede consultar el trabajo de AlCALDE Rodríguez, Enrique (2009). "Algunas consideraciones en torno a la identidad sustancial entre la sanción penal y la pena administrativa”. En Arancibia Mattar, Jaime y Martínez Es- 


\subsection{2.) La jurisprudencia constitucional}

Cuestión distinta es lo que ocurre en la jurisprudencia, particularmente aquella que ha emanado del Tribunal Constitucional. En sus sentencias este órgano ha utilizado un concepto amplio y en otros restringido de sanción administrativa, considerando las garantías a las cuales se encuentran sujetos los destinatarios de las normas administrativas que regulan este tipo de sanción.

Tratándose de las garantías de carácter procedimental (racional y justo procedimiento), el Tribunal ha utilizado un concepto amplio de sanción administrativa. En efecto, bajo un particular concepto de jurisdicción, ha entendido por sanción administrativa todo acto con efectos desfavorables que emane de los órganos de la Administración del Estado. El razonamiento que sigue el Tribunal Constitucional es que las expresiones "sentencia de un órgano que ejerza jurisdicción", contenidas en el inciso $5^{\circ}$ del numeral $3^{\circ}$ del artículo 19 de la Carta Fundamental, deben entenderse en un sentido amplio, como "[...] sin limitación alguna, al ejercicio de la jurisdicción -esto es, el poder-deber de conocer y resolver cualquier conflicto de carácter jurídico- por cualquier órgano, sin que importe su naturaleza, y se refiere a sentencia no en un sentido restringido, sino como a toda resolución que decide una controversia de relevancia jurídica”. Así, el Tribunal entiende incluidas resoluciones tales como la que adopta el Ministro de Transportes y Telecomunicaciones cuando otorga o deniega una concesión o un permiso de telecomunicaciones ${ }^{13}$.

De esta forma, el Tribunal Constitucional sostiene que la expresión jurisdicción comprende a toda entidad, pública o privada, que ejerce potestad resolutiva sobre determinados asuntos que se pueden imponer a terceros. Así, cuando la Administración ejerce sus potestades públicas, estaría ejerciendo jurisdicción y debe responder a las garantías de un racional y justo procedimiento. En buenas cuentas, el ejercicio de un poder público siempre exige que los afectados por dicha determinación tengan ciertas garantías procesales mínimas, como la posibilidad de audiencia, defensa, etc. En este caso concreto, estas garantías se manifiestan dentro

tay, José Ignacio (coordinadores): La primacía de la persona. Estudios en homenaje al profesor Eduardo Soto Kloss. Santiago de Chile: LegalPublishing, pp. 795-808.

13 Tribunal Constitucional. 31 de agosto de 2007. Rol No 747-07. "Requerimiento de inaplicabilidad presentado por María Isabel Reyes Kokisch respecto del inciso tercero del artículo 551; inciso segundo del artículo 539; inciso segundo del artículo 541; inciso segundo del artículo 539; artículos 536, 537 y 542; número $4^{\circ}$ del artículo 544; artículos 557 y 558, todos del Código Orgánico de Tribunales, en la causa Antecedentes de Pleno Rol No 19202006 ad, seguida ante el Ministro en Visita don Juan Escobar Zepeda". Considerando 5, con referencia a los precedentes contenidos en las Sentencias Rol Nos. 176, de 1993; y 478, de 2006. 
del procedimiento administrativo. Así, por lo demás, lo ha confirmado en la Sentencia Rol No437, de 2005, en donde señala:

“[...] los principios del artículo 19 No 3 de la Constitución, en la amplitud y generalidad ya realzada, se aplican, en lo concerniente al fondo o sustancia de toda diligencia, trámite o procedimiento, cualquiera sea el órgano estatal involucrado, trátese de actuaciones judiciales, actos jurisdiccionales o decisiones administrativas en que sea, o pueda ser, afectado el principio de legalidad contemplado en la Constitución, o los derechos asegurados en el artículo 19 No 3 de ella, comenzando con la igual protección de la ley en el ejercicio de los atributos fundamentales. Además y de los mismos razonamientos se sigue que los principios contenidos en aquella disposición constitucional rigen lo relativo al proceso racional y justo, cualquiera sea la naturaleza, el órgano o el procedimiento de que se trate, incluyendo los de índole administrativa, especialmente cuando se ejerce la potestad sancionadora o infraccional' 14.

Sin perjuicio de las críticas que se han formulado a este particular concepto de jurisdicción, sobre todo por las proyecciones que tiene respecto del gran abanico de atribuciones y potestades que ejerce la Administración ${ }^{15}$, en esta ocasión nuestro interés se va a centrar en el concepto de sanción administrativa que subyace en los pronunciamientos de este Tribunal.

A este respecto, el Tribunal Constitucional ha calificado como sanciones diversas actuaciones de la Administración, las que no se enmarcan necesariamente en el concepto sostenido por la doctrina. Así, ha calificado como sanción administrativa algunas medidas que tienden al restablecimiento del orden jurídico sin que tengan un carácter reaccional ${ }^{16}$

14 Tribunal Constitucional. 21 de abril de 2005. Rol No437. "Requerimiento de inconstitucionalidad formulado por doce seńores Senadores respecto del proyecto de ley que modifica el Decreto con Fuerza de Ley No 458, de 1975, Ley General de Urbanismo y Construcciones". Considerando 17.

15 Sobre este particular, se puede consultar el trabajo de Bordali, Andrés y Ferrada, Juan Carlos (2008) Estudios de Justicia Administrativa. Santiago de Chile: LexisNexis, pp. 87-88.

16 Así ocurrió en el Sentencia Rol No38 de 1986, respecto del proyecto de Ley Orgánica Constitucional sobre Sistema de Inscripciones Electorales y Servicio Electoral (actual Ley No18.556). Dicho proyecto facultaba al Director del Servicio Electoral para disponer la cancelación de las inscripciones electorales, entre otras razones, por haber practicado una inscripción electoral en contravención a dicha ley. A este respecto, el Tribunal Constitucional sostuvo que dicha norma lo autorizaba "para apreciar tanto los hechos como el alcance de las normas de esta ley a fin de resolver si se ha practicado o no una inscripción en contravención a ella" (Considerando 22\%). En tal sentido, sostiene que aquello vulnera los incisos $1^{\circ}$ y $5^{\circ}$ del numeral 3 del artículo 19 de la Constitución porque "[...] no establece normas que le aseguren a quien resulte afectado por la resolución del Director del Servicio Electoral un justo y racional procedimiento, ya que no contempla, entre otras garantías, ni el emplazamiento a la persona respectiva, ni la oportunidad para defenderse ni tampoco la posibilidad de deducir recurso alguno ante otra autoridad para reclamar de una eventual cancelación indebida" (Considerando 24\%). 
o incluye determinadas medidas provisionales que se pueden adoptar mientras son objeto de revisión judicial ${ }^{17}$. No obstante, también ha comprendido aquellas sanciones administrativas en sentido estricto, conforme al concepto que se ha formulado ${ }^{18}$. En todos estos casos, el Tribunal ha hecho aplicación de las garantías de un racional y justo procedimiento administrativo previo, conforme al alcance amplio que se da al inciso $5^{\circ}$ del No3 del artículo 19 de la Constitución ${ }^{19}$.

Por su parte, en el caso de las garantías sustantivas (legalidad, tipicidad, responsabilidad personal, etc.) el Tribunal ha seguido muy de cerca la doctrina y jurisprudencia espańola, particularmente del Tribunal Constitucional Español, limitándose al concepto estricto de sanción administrativa, entendida como una manifestación del ius puniendi estatal, sujeto con "matices" a los principios inspiradores del orden penal ${ }^{20}$.

\subsection{3) La jurisprudencia administrativa}

La capital importancia que tiene en Chile la jurisprudencia administrativa que emana de la Contraloría General de la República es indiscutible, al punto de transformarse en la práctica en un auténtico contencioso-administrativo, asociado además a la calidad y autoridad de sus dictámenes.

Ahora bien, considerando la función que tiene asignada, la Contraloría General de la República ha emitido una gran cantidad de dictámenes

17 En la Sentencia Rol No43 de 1987, señala que "como puede apreciarse, la norma entrega a la competencia del Director del Servicio Electoral apreciar hechos y efectuar una valoración jurídica de ellos, para determinar, provisionalmente, si hubo o no alteración dolosa en las declaraciones de afiliación a un partido en formación, con la grave consecuencia de que sí concluye que hubo la solicitud de inscripción del partido político se tiene por no presentada [...] teniendo presente las disposiciones constitucionales transcritas en el considerando anterior, lleva a la ineludible conclusión que él infringe los incisos $1^{\circ}$ y $5^{\circ}$ del $\mathrm{N}^{\circ} 3$ del artículo 19 de la Carta Fundamental, porque no establece normas que le aseguren al partido político en formación que resulte afectado un justo y racional procedimiento, ya que no contempla ni el emplazamiento de dicho partido en formación ni tampoco la oportunidad para defenderse" (Considerando 61 y 63).

18 Véase Sentencias Rol No376, de 2003; No389, de 2003; No415, de 2004; y No434, de 2005.

19 Sobre esta materia, se puede consultar el trabajo de AguerreA, Pedro (2005). "Límites procesales a las potestades sancionadoras de la Administración en la jurisprudencia del Tribunal Constitucional". En AA.VV. Sanciones Administrativas y Derechos fundamentales: regulación y nuevo intervencionismo. Santiago de Chile: Universidad Santo Tomás, 171 pp., pp. 73-96. Cabe tener presente que el Tribunal Constitucional Español también ha extendido, aunque para casos muy excepcionales, garantías propias del Derecho sancionador a actos no sancionadores. Una relación de la jurisprudencia se puede ver en Rebollo Puig, Manuel y otros (2010) Derecho Administrativo Sancionador. Madrid: Lex Nova, 1024 pp., pp. 58-59.

20 Comparar con Sentencias Rol Nos. 244, de 1996; 479 y 480, de 2006; 725 y 766, de 2008; $1.183,1.184,1.203,1.205,1.221$ y 1.229 , de 2009; y 1.518, de 2010. 
vinculados al ejercicio de la potestad sancionadora por parte de los órganos de la Administración del Estado. En una primera etapa, la doctrina de Contraloría se centró en el ejercicio de la potestad disciplinaria, estableciendo un conjunto de principios al cual debía someterse, obtenidos en su mayoría del Derecho penal, aun cuando no se menciona expresamente esta circunstancia ${ }^{21}$. En un segundo período, sigue muy de cerca al Tribunal Constitucional y el ente contralor sostiene que la potestad disciplinaria es una manifestación de la potestad sancionatoria del Estado, la que, a su vez, es junto a la potestad punitiva penal, una de las manifestaciones del ius puniendi general del Estado, razón por la cual ha entendido también que los principios del derecho penal son aplicables al derecho sancionador disciplinario ${ }^{22}$. En esta nueva línea, la Contraloría busca dar un sustento teórico-normativo al régimen de las sanciones administrativas, recurriendo a la doctrina comparada, particularmente espańola (Miguel Sánchez Morón, Alejandro Nieto y Juan J. Zornoza Pérez); a la doctrina nacional (Ramiro Mendoza y Blanca Oddo) y a la jurisprudencia del Tribunal Constitucional, contenida en su Sentencia Rol No244, de 1996.

Sin embargo, no existe en estos dictámenes algún pronunciamiento expreso respecto del concepto de sanción administrativa que sirve de base a los mismos. Tal como lo hemos señalado, en su gran mayoría los dictámenes han recaído respecto del ejercicio de la potestad disciplinaria, la cual se corresponde plenamente con el concepto estricto de sanción administrativa. Con posterioridad se ha extendido a la potestad sancionatoria que se ejerce sobre particulares, conocida bajo la expresión de sanciones gubernativas. En este último caso, la Contraloría también ha establecido principios y criterios bajo la idea subyacente que nos encontramos ante sanciones administrativas propiamente tales ${ }^{23}$. Pero también ha comprendido dentro del concepto de sanción determinados actos de efectos desfavorables, que no son sanciones stricto sensu, como son las medidas destinadas a restablecer el orden jurídico mediante la clausura de un es-

21 En su dictamen No14.571, de 2005, hace un relación de los mismos: irretroactividad de las normas sancionadoras (Dictámenes Nº. 45.905 y 88.303, ambos de 1976, 20.991 de 1984, 25.961 de 2000, 3.858 y 6.926, ambos de 2001, y 38.075 de 2002, entre otros)-; el principio non bis in idem (Dictámenes $\mathrm{N}^{\circ}$ s. 27.108 de 1969, 21.815 de 1983, y 41.736 de 2004); la prohibición de la analogía en cuanto a las sanciones (Dictámenes $\mathrm{N}^{\circ}$ s. 21.464 de 1989, y 29.136 de 1999), y el principio pro reo (Dictámenes $\mathrm{N}^{\circ}$ s. 81.058 de 1974, 16.141 de 1977 y 20.991 de 1984), entre otras materias.

22 Véase Dictamen No50.013 bis, de 2000. En el mismo sentido se pueden consultar los Dictámenes $\mathrm{N}^{\circ}$ s.28.226, de 2007; 62.188, de 2009; y 63697, de 2011.

23 Esto se puede ver claramente en lo que ocurre en materia sanitaria (Dictámenes $\mathrm{No}^{\text {s. }}$. 28.226, de 2007; 62.188, de 2009; 58.795, de 2010; y 79158, de 2010); en el sector eléctrico (Dictamen No63.697, de 2011); de los instaladores de gas (Dictamen No14.571, de 2005); del sector comercial (Dictamen No46.300, de 2002), entre otros. 
tablecimiento ${ }^{24}$ o la declaración de caducidad de una autorización ${ }^{25}$. No obstante, se debe tener presente que en estos últimos casos la calificación de sanción hecha por la Contraloría no ha sido determinante en su decisión, pues estos problemas se han centrado básicamente en el respeto del principio de legalidad en el actuar de la Administración.

Conforme a lo expuesto, en nuestra opinión subyace en la jurisprudencia de Contraloría un concepto amplio de sanción administrativa, especialmente para dar ciertos resguardos frente a los actos administrativos de efectos desfavorables. Pero también el ente contralor ha insinuado un concepto sustancial de sanción administrativa centrada en la significación ético-social reducida que tiene frente a las penas, aunque reconoce que corresponde al legislador hacer esta separación o deslinde ${ }^{26}$.

\subsection{4) La jurisprudencia judicial}

Sobre esta materia, la jurisprudencia judicial ha seguido el concepto estricto de sanción administrativa. Esto ocurre especialmente con los pronunciamientos de la Corte Suprema, la cual se ha centrado en una doble función que deben cumplir estas sanciones: una de carácter preventivo respecto de determinadas conductas consideradas como ilícitos administrativos, y otra de carácter represivo, en respuesta a la infracción cometida.

En tal sentido, la Corte Suprema ha señalado que "[...] la sanción administrativa tiene principalmente una finalidad preventivo-represora, con ella se persigue el desaliento de futuras conductas ilícitas similares, se busca reprimir la conducta contraria a derecho y restablecer el orden jurídico previamente quebrantado por la acción del transgresor" 27.

Sin perjuicio de lo anterior, la Corte Suprema parte del supuesto que se trata de una potestad punitiva entregada a un órgano de la Administración del Estado, siguiendo las formas y el procedimiento propios de entidades de esta naturaleza. Más aún, ha recalcado de forma estricta la aplicación de los principios contenidos en la Ley Orgánica Constitucional de Bases Generales de la Administración No18.575 y de la Ley No19.880,

24 Véase Dictamen $\mathrm{N}^{\circ}$ s. 8.929, de 1999 y 46.300, de 2002.

25 Véase Dictamen 29.136, de 1999.

26 En su Dictamen No28.226, de 2007, la Contraloría señala que "[...] la distinción de estos dos ámbitos sancionatorios (penal y administrativo) obedece exclusivamente a un criterio cuantitativo, puesto que el ilícito administrativo, comparado con el de naturaleza penal, es un injusto de significación ético-social reducida, que por razones de conveniencia y de política legislativa se ha encargado a la Administración".

27 Corte Suprema. 15 de septiembre de 2010. Rol No 4.922-2010, considerando 6º En el mismo sentido, se pueden ver las sentencias de 29 de octubre de 2010 , causa Rol No 9.078 2009, considerando $9{ }^{\circ}$ y, de la misma fecha, la causa Rol No 2.090-2010, considerando $9^{\circ}$. 
que establece las bases de los procedimientos que rigen a los actos de la Administración del Estado ${ }^{28}$.

\section{2) Las SANCiOnes Administrativas y las PenaS}

\subsection{1) Aspectos generales}

Una vez realizada la formulación del concepto de sanción administrativa a partir de la distinción con otras actuaciones de la Administración del Estado, particularmente aquellas que contienen efectos desfavorables para los particulares, corresponde dar un segundo paso, claramente más complejo y cuya discusión es de antigua data. Me refiero a la distinción que se puede formular entre sanciones administrativas y penas.

Como ocurre en la mayor parte de los países de nuestro entorno, el ordenamiento jurídico chileno reconoce la existencia de dos manifestaciones del poder punitivo del Estado. En primer lugar, se encuentra aquel entregado a los tribunales de justicia, conforme a la tradición revolucionaria liberal y sujeta a una serie de principios y garantías (legalidad, tipicidad, culpabilidad, irretroactividad, non bis in idem, indubio pro reo, etc.), que conforman el Derecho penal liberal y judicializado. Por otra parte, nos encontramos con la potestad punitiva de la Administración, a cuyos órganos se le atribuye la facultad para determinar la existencia de infracción al orden jurídico y sancionarlas directamente, sin la intervención de la autoridad judicial.

La coexistencia de ambos poderes siempre ha planteado una suerte de paradoja, que enfrenta los principios liberales en que se inspira el poder punitivo del Estado, frente a una realidad cada vez más intensa en la atribución de potestades sancionatorias en manos de la Administración del Estado, más aún si este último reducto ha estado lastrado por el estigma de ser un espacio carente de las más mínimas garantías para los particulares, al punto de ser calificado como un "Derecho represivo prebeccariano" 29 . No obstante la notable evolución que se ha experimentado en esta materia, a través de la aplicación "matizada" de los principios del orden penal al ámbito de este tipo de sanciones, sigue siendo persistente el problema de determinar si las sanciones administrativas son un tipo de sanción penal o su naturaleza es diversa.

Los estudios sobre el régimen de las infracciones administrativas en Chile son claramente tributarios de la doctrina y jurisprudencia extranjera y, por tanto, de la discusiones tradicionales que se han planteado sobre la materia, especialmente acerca de la naturaleza de estos ilícitos. Así, no

\footnotetext{
28 Ídem.

29 García de Enterría/Fernández (1999) 167.
} 
es extraño encontrar la exposición clásica que trata de separar, a partir de un criterio sustancial, los ilícitos administrativos de los penales -especialmente por parte de autores italianos como Ranelletti y Girola ${ }^{30}$ o señalar en su caso que la distinción es de carácter estrictamente formal: las penas las aplica el juez, mientras que las sanciones administrativas la Administración -concepción de clara influencia germana, especialmente de la obra de Adolf MerkL-31.

Ahora bien, estos trabajos llegaron a Chile fundamentalmente de forma mediata, especialmente a través la doctrina española ${ }^{32} \mathrm{y}$, en algunos casos, italiana ${ }^{33}$. Sin embargo, muchas de estas concepciones aparecen bastante desdibujadas, entremezcladas y sin indicación de su fuente original.

Para tratar este punto, vamos a seguir el mismo camino, analizando la forma como el tema ha sido comprendido por la doctrina nacional, la jurisprudencia constitucional, administrativa y judicial.

\subsection{2) La discusión en la doctrina nacional}

Los penalistas nacionales han asumido el estudio del tema a partir de lo dispuesto en el artículo 21 del Código Penal, norma que establece que no se reputan penas, entre otras, las multas y demás correcciones que los superiores impongan a sus subordinados y administrados en uso de su jurisdicción disciplinal o atribuciones gubernativas. Llevados a la cuestión, los penalistas se han hecho cargo con una mayor profundidad, recurriendo directamente a doctrina comparada, especialmente alemana ${ }^{34}$. En todo caso, todavía no existe entre ellos una solución o propuesta dogmática definitiva, razón por la cual autores como Enrique CuRY sostiene que la

30 Ranelletti, O. (1904). "La polizia di sicurezza”. En Orlando, V. E. (director) Primo trattato completo di diritto amministrativo italiano. Milano: Libraria, y Girola, C. (1929). "Sanzioni penali e sanzioni amministrative”. Rivista di Diritto Pubblico, I, pp. 429 y ss.

31 Merkl, Adolf (2004) Teoría general del Derecho Administrativo, traducción de su obra Allgemeines Verwaltungsrecht, Wien \& Berlin: Springer, 1927. Granada: Comares, 2004, p. 351.

32 Especialmente se pueden ver los trabajos de Fernando Garrido Falla en diversos artículos científicos, los cuales se condensan en su Garrido Falla, Fernando (2002) Tratado de Derecho Administrativo, $11^{\text {a }}$ edición, Vol. II. Madrid: Tecnos. La primera edición data de 1960.

33 Esto ocurre con Zanobini, Guido (1924) Le sanzioni amministrative. Roma: Bocca. Por lo demás, a través de esta obra llega parte de la doctrina alemana, como es el caso de GoldsснміDт, James (1902) Das Verwaltungsstrafrecht: eine Untersuchung der Grenzgebiete zwischen Strafrecht und Verwaltungsrecht auf rechtsgeschichtlicher und rechtsvergleichender Grundlage. Berlin: Heymanns.

34 Cousiño Mac Iver, Luis (1975) Derecho penal chileno. Parte general. Santiago de Chile: Editorial Jurídica de Chile, pp. 23-29; Cury Urzúa, Enrique (2005) Derecho penal. Parte general, 8a edición. Santiago de Chile: Ediciones Universidad Católica de Chile, pp. 100116; Etcheberry Orthústegui, Alfredo (1998) Derecho penal, $3^{\text {a }}$ edición. T. II, Santiago de Chile: Editorial Jurídica de Chile, pp. 131-169; Novoa Monreal, Eduardo (1985) Curso de Derecho penal chileno, 2a edición. Santiago de Chile: Ediar-ConoSur. 
distinción entre pena penal, la administrativa y la disciplinaria ha llegado a constituirse en un problema cuyas consecuencias prácticas son graves y cuya solución teórica, entretanto, dista de ser unánime y satisfactoria ${ }^{35}$.

En esta materia, uno de los trabajos más interesantes ha sido el desarrollado por Luis Rodríguez Collao, quien analiza el problema a partir del concepto de pena y las diversas acepciones que esta puede tener ${ }^{36}$. En términos generales, este autor entiende que, desde el punto de vista jurídico, la palabra pena es "sinónimo de castigo, es decir, una medida aflictiva que debe soportar todo aquel que incurre en una conducta indebida". En un segundo nivel, se encuentran las penas que el Estado aplica a su súbditos, las cuales comprenden no solo las penas penales, sino también las penas o sanciones que aplica la Administración. Por último, se encontraría el concepto más restringido de pena, que comprende aquellas que impone el ordenamiento jurídico penal.

Refuerza esta distinción, la interpretación que el mismo autor hace del artículo 20 del Código Penal, ya que esta disposición establece que no se reputan penas "las multas y demás correcciones que los superiores impongan a sus subordinados y administrados en uso de su jurisdicción disciplinal o atribuciones gubernativas", es decir, no se reputan penas, para efectos penales, las sanciones que aplica la Administración. En tal sentido, los propios términos de la norma implican un reconocimiento en orden a que el concepto de pena puede tener un alcance más amplio que el que le asigna el Código Penal ${ }^{37}$. En el mismo sentido, Enrique CURY señala que el artículo 20 no considera a las sanciones administrativas formalmente penas, aunque reconoce que participan de la misma naturaleza ${ }^{38}$.

De esta forma, situados en el segundo nivel de esta tripartición, no parece existir inconveniente en llamar penas al castigo que dispensan los tribunales de justicia y las sanciones que aplican los órganos de la Administración del Estado. Además, esta distinción permite al autor entender que el concepto constitucional de pena, tal como se contiene el artículo 19 de la Constitución, particularmente en su numeral $3^{\circ}$, se corresponde con esta categoría intermedia y proyecta su estatuto de garantías tanto a las penas penales como a las penas administrativas.

Por su parte, el tema en la doctrina administrativa ha sido objeto de discusiones extremas. El planteamiento más radical viene de la mano de

Cury (2005) 100.

RodríGuez (1987) 122

RoDríguez (1987) 123.

CURY (2005) 107. El mismo autor señala que si el legislador hubiera creído en verdad que esas reacciones jurídicas eran cualitativamente diferentes de la pena criminal, el precepto lo habría consignado mediante el giro "no son penas" u otro equivalente que, incluso, habría resultado superfluo. Pero el empleo del verbo reputar en el encabezamiento de la norma subraya el carácter artificioso de la distinción, pues significa que a tales sanciones no se les tendrá por penas no obstante que naturalmente lo son. 
Eduardo Soto $\operatorname{KLoss}^{39}$, seguido en esta materia por Iván Aróstica ${ }^{40}$. Para estos autores las sanciones administrativas son derechamente penas. En palabras de Sото Kloss, sancionar "no es otra cosa que "castigar", y castigo es, sin duda, pena, un agravio, en razón de haberse producido una violación a un mandato u orden preestablecido. La idea misma de "sanción", en este sentido, conlleva la de "reprimir" una conducta -e incluso una omisión, cuando se tiene la obligación de actuar- a fin de imponer lo debido/lo justo a una infracción o vulneración de algo mandado o impuesto". En definitiva, sancionar/castigar significa imponer una pena.

Sin embargo, el análisis y objetivo de estos autores no tiene por finalidad establecer o determinar el régimen jurídico aplicable a este tipo de sanciones, sino que tacharlas derechamente de inconstitucionales. En esta línea, los órganos de la Administración del Estado estarían ejerciendo facultades privativas que la Constitución entrega a los tribunales de justicia (artículo 73 y 19 No3 inciso 4 Const.). En definitiva, toda sanción es pena y, a su vez, la aplicación de una pena es un acto jurisdiccional que solo corresponde a los tribunales de justicia y no a la Administración. Por lo demás, esto explica la reacción que algunas autores han manifestado a esta posición, ya sea desde el Derecho penal ${ }^{41}$ como del Derecho administrativo $^{42}$.

\subsection{3) La jurisprudencia constitucional}

En sus primeros pronunciamientos sobre la materia, el Tribunal Constitucional acogió la doctrina y jurisprudencia española sobre el carácter unitario del ius puniendi estatal, el cual se manifiesta en sus dos vertientes: una penal y otra administrativa ${ }^{43}$. En buena medida, esta posi-

Soto Kloss (1979/1980) (2005).

Aróstica (1987).

Rodríguez (1980) 130.

Román Cordero (2008) 107-141.

Sentencia Rol No244, de 2006, considerando 9․ Esto después se reafirma en las Sentencias Rol Nos. 479 y 480, ambos de 2006. Esta regla básica tiene su origen en la jurisprudencia del Tribunal Constitucional Espańol (Sentencias de 30 de enero y 8 de junio, de 1981), la que a su vez fue tomada de la jurisprudencia preconstitucional del Tribunal Supremo Español. La Sentencia del Tribunal Supremo de 31 de octubre de 1972 señalaba a este respecto que "el supuesto de hecho de que se trata [...] pertenece al capítulo especial del Derecho Administrativo, esto es, al Derecho administrativo sancionador, llamado también por muchos Derecho penal administrativo, no sin falta de fundamento, puesto que, a lo largo de la historia, se presenta todo un trasiego de infracciones del Derecho penal común, al Derecho que acabamos de llamar penal administrativo, o viceversa [...] lo que revela la necesidad imperiosa de que existan unos principios generales, y un cuerpo de doctrina que cubran uno u otro campo, por darse en los dos unas mismas exigencias, como son el principio de legalidad [...] ya que, si por un lado, el derecho sancionador representa la protección más enérgica de los bienes necesitados de una protección especial, por otro, este 
ción sustenta la identidad ontológica entre las penas penales y las sanciones administrativas, bajo la formulación de un tronco común que permite proyectar los principios del orden penal a estas últimas.

No nos corresponde ahora discutir esta doctrina, aunque cabe advertir que no deja de generar una serie de dificultades a partir de una concepción metanormativa que permite sustentar esta identidad ontológica entre infracciones y delitos, por un lado, y sanciones y penas, por otro. Más aún, si luego se proyectan unos principios matizados al orden administrativo que se alejan del ámbito penal, sin dar mayor certeza sobre la forma de realizar estas modulaciones o matices.

Ahora bien, esta idea de la identidad ontológica se ve ratificada por el propio Tribunal Constitucional, que señala que "[...] las sanciones administrativas participan de las características esenciales de las sanciones penales al ser ambas emanaciones del ius puniendi estatal, por lo que debe aplicarse, con matices, similar estatuto [...]"44, llamándola derechamente "penas" 45 .

Conforme a este criterio, el elemento determinante entre una pena penal y una pena administrativa vendría dado por la autoridad que está llamada a aplicarla. En el primer caso la autoridad judicial, mientras que en el segundo caso sería la autoridad administrativa. Si esto se analiza desde el punto de vista del derecho positivo, más allá de las valoraciones ético-sociales que pueda significar, no existiría un límite sustantivo para que el legislador pueda moverse de forma discrecional entre las sanciones penales y las administrativas para castigar determinadas conductas, lo cual no se condice con el sentido que tienen los principios y garantías propias del Derecho penal frente a un criterio más laxo o de garantías mínimas, como ocurre con las sanciones administrativas, más aún si consideramos que buena parte de las garantías penales están reconocidas a nivel constitucional y en sendos tratados internacionales. Extremando más aún las cosas, una concepción que identifica ontológicamente las sanciones penales y las administrativas, puede transformarse en un tentador espacio para que el legislador despenalice determinadas conductas y las sancione por

mismo rigor demanda, en contrapartida, las máximas garantías para el encausado, entre ellas, además de las antes apuntadas, la que puede considerarse como idea básica de todo el derecho punitivo y sancionador: la que fundamenta el principio «in dubio pro reo»". Esta teoría de la identidad ontológica entre infracción administrativa y delito es sostenida actualmente en España por la mayoría de la doctrina y la totalidad de la jurisprudencia, aun cuando ha sido duramente criticada en el último tiempo, especialmente a partir de los trabajos del profesor Alejandro Nieto en su trabajo titulado Derecho administrativo sancionador, que va en su cuarta edición, siendo la primera de 1993 (Madrid: Tecnos), y que ha sido de obligada referencia en las obras y comentarios posteriores.

44 Tribunal Constitucional. 21 de octubre de 2010. Rol No1518-09. Considerando 6º

45 TC. Rol No1518-09, considerando 7o. 
la vía administrativa, sin más límite que su conciencia ética, cuestión del todo impresentable y absurda.

Es en este punto donde el Tribunal Constitucional ha hecho un notable avance, estableciendo de forma clara y precisa que no es posible que se imponga una pena privativa de libertad por la vía administrativa, sin que previamente exista una instancia jurisdiccional que revise dicha actuación ${ }^{46}$. En buenas cuentas, una infracción administrativa no puede tener como sanción una pena privativa de libertad, ni tampoco puede considerarse como medida de apremio dicha posibilidad ${ }^{47}$.

Tal como lo comentaremos más adelante, esto abre un amplio abanico de posibilidades de acción para el legislador, con el objeto de establecer una política represiva como instrumento de control social en el marco de los valores y bienes constitucionales reconocidos, sujeto a una serie de límites sustantivos al momento de graduar la sanciones que va a establecer con el objeto de cumplir dicha finalidad. En definitiva, el legislador puede establecer ilícitos y sanciones, entregando su determinación y castigo a la autoridad judicial o administrativa, valorando discrecionalmente la conveniencia, oportunidad y eficacia de seguir uno u otro camino. Sin embargo, en el caso de establecer las sanciones más graves, esto es, la

46 TC. Rol No1518-09, considerando $22^{\circ}$.

47 El pronunciamiento del Tribunal Constitucional se pronuncia sobre la constitucionalidad del artículo 169 del Código Sanitario, el cual permitía, por la vía administrativa, sustituir la multa por una medida de apremio consistente en un día de prisión por cada décimo de unidad tributaria mensual que comprenda dicha multa, sin intervención de la autoridad judicial. En términos generales, el Tribunal sostuvo que este apremio "[..] no puede considerarse de aquellos amparados por el orden constitucional y, por consiguiente, legítimo, toda vez que consiste en una limitación a la libertad que en sí misma no tiene la finalidad propia de un apremio, esto es, compeler a un individuo a realizar una determinada conducta, sino más bien, como ya se señaló, es una pena privativa de libertad utilizada como forma de apremio o presión, por lo que en sí misma importa una reacción punitiva ante una conducta del individuo que viene a reemplazar por vía de sustitución el pago de una multa y que, por consiguiente, su finalidad es más bien sancionar al responsable de un acto. De esta manera, mal podría considerarse que se está en presencia de un apremio legítimo si este a su vez importa el castigo de una conducta que, como se apreciará, no es aún del todo reprochable, desde el momento que se ha impetrado a la jurisdicción ordinaria con el objeto de que esta determine si existe realmente una determinada responsabilidad imputable a los recurrentes [...] Que, a mayor abundamiento, la pena de prisión, utilizada como un apremio, tampoco puede considerarse ajustada a la Constitución, atendido que el precepto reprochado no establece la intervención de la autoridad judicial que decrete la respectiva privación luego de determinar, conforme al mérito de un proceso, la tipicidad de la conducta, su antijuridicidad y la culpabilidad del sujeto". Por último, señala que "[..] tampoco puede esta Magistratura estimar como legítimo un apremio-pena que se ha originado en una conducta cuya ilicitud aún no goza de verdad judicial, desde el momento que los requirentes reclamaron de las multas impuestas y se encuentra pendiente el respectivo pronunciamiento jurisdiccional. Así, al no existir sentencia judicial que se pronuncie sobre los hechos que motivan la sanción, no resulta lícito que esta última se haga efectiva y exigible desde ya y compulsivamente a través de un "apremio", que por demás consiste en una verdadera pena privativa de libertad impuesta por vía administrativa” (TC. Rol No1518-09, considerandos 17º $18^{\circ}$ y $19^{\circ}$ ). 
privación de libertad como instrumento de sanción o castigo, la única vía posible será la de los tribunales de justicia, con todas las garantías sustantivas y procedimentales que establece la Constitución y la ley. De esta forma, se asegura uno de los principios básicos del sistema constitucional, como es la proporcionalidad de las medidas adoptadas para cumplir un fin determinado, en relación con la forma e intensidad en que los derechos fundamentales se pueden ver afectados. Además, coloca al Derecho penal como ultima ratio o con el carácter subsidiario que le es propio. Así, por lo demás, lo ha entendido al Tribunal Constitucional al señalar:

"Que, además, se ha sentenciado que un apremio que importe privación de libertad, debe decretarse "con una indudable determinación y con parámetros incuestionables, esto es, respetando el principio de proporcionalidad entre la limitación del derecho fundamental a la libertad y el objetivo constitucionalmente válido que se busca perseguir". En tal sentido, se ha señalado que una limitación a un derecho fundamental es justificable cuando dicho mecanismo "es el estrictamente necesario o conveniente para lograr un objetivo constitucionalmente válido, debiendo consecuentemente el legislador elegir aquellas limitaciones que impliquen gravar en menor forma los derechos fundamentales" (sentencias roles Nos. 519 y 576)" 48.

En definitiva, para el Tribunal Constitucional hay una identidad ontológica entre las penas y las sanciones administrativas, en la medida que ambas participan del estatuto constitucional de las penas previstos en la Carta fundamental, sujeto a algunos matices. A su vez, en el marco de una política represiva que permite satisfacer y cumplir con los fines constitucionales, el legislador puede configurar y sancionar determinadas conductas ilícitas, radicando discrecionalmente su aplicación ante la autoridad judicial y administrativa, respetando dos reglas básicas: a) las penas privativas de libertad siempre deben ser judicializadas; y b) se debe respetar el principio de proporcionalidad entre la limitación del derecho fundamental y el objetivo constitucionalmente válido que se busca perseguir.

\subsection{4) La jurisprudencia administrativa}

En relación a las penas y las sanciones administrativas, la Contraloría ha seguido la tesis del ius puniendi único del Estado y, por tanto, de la identidad ontológica entre ambas, siguiendo en esta materia la jurisprudencia constitucional y la doctrina nacional y extranjera ${ }^{49}$.

En tal sentido, el ente contralor ha señalado que "[...]El origen histórico de las sanciones administrativas como un simple desplazamiento de

\footnotetext{
48 TC. Rol No1518-09, considerando $10^{\circ}$.

49 Véase Dictámenes Nos. 50.013 bis, de 2000; 14.571, de 2005; 28.226, de 2007; y 63.697, de 2011.
} 
la competencia desde el ámbito de los tribunales hacia el de la Administración, justificado por razones de conveniencia y de política legislativa $[\ldots] " 50$.

Sin embargo, también ha reconocido que existen elementos de carácter sustantivos para hacer esta segregación o desplazamiento: "[...] la distinción de estos dos ámbitos sancionatorios obedece exclusivamente a un criterio cuantitativo, puesto que el ilícito administrativo, comparado con el de naturaleza penal, es un injusto de significación ético-social reducida, que por razones de conveniencia y de política legislativa se ha encargado a la Administración" 51 . En ese aspecto, la Contraloría reconoce que no hay delitos ni infracciones por naturaleza, pues estos son establecidos y configurados como tales por el legislador. Además, en esta labor es el propio legislador quien valora estas conductas y considerando su gravedad, entrega su conocimiento y aplicación a los jueces o a la Administración. Es, en definitiva, una cuestión de política legislativa sujeta, empero, al marco constitucional.

Por su parte, también reconoce que en el ámbito administrativo los principios y garantías son más atenuadas que en materia penal, sin embargo esto no puede significar que no existan garantías mínimas que deben ser respetadas: "[...] aun cuando en materia administrativa se admite cierta atenuación de los principios que limitan la potestad del Estado para aplicar sanciones, tolerando mayores grados de discrecionalidad, lo cierto es que de ninguna manera ello se podría traducir en la desaparición de tales principios, puesto que sería del todo ilógico que el infractor administrativo carezca de derechos y garantías que se reconocen al delincuente, o que el juez penal tuviera límites que no se apliquen al órgano administrativo sancionador" 52 .

Por lo tanto, la Contraloría comparte los criterios seguidos por la jurisprudencia constitucional en esta materia, reconociendo que la separación entre sanciones penales y administrativas es una cuestión de política legislativa. Además, el reproche ético-social de los ilícitos administrativos es menor, con lo cual se atenúan ciertos principios y garantías, pero que no desaparecen totalmente.

\subsection{5) La jurisprudencia judicial}

La Corte Suprema no plantea mayor novedad a este respecto. Tal como sostiene en sus fallos, desde antiguo subyace en sus sentencias la idea del ius puniendi único del Estado, que permite proyectar los prin-

Contraloría General de la República. 22 de junio de 2007. Dictamen No28.226.

CGR. Dictamen No28.226, de 2007.

CGR. Dictamen No28.226, de 2007. 
cipios y normas del orden penal al ámbito de las sanciones administrati$\mathrm{va}^{53}$. Esto supone también la tesis de la identidad ontológica de ambos tipos sancionatorios, aunque en algunas sentencias ha matizado este punto: "[...] si bien principios elementales entre una y otra son comunes y lógicos, como ocurre con los relativos al non bis in idem, a la irretroactividad de la ley sancionadora, al principio pro reo y a la necesidad de prescripción de la respectiva acción persecutoria, no es posible desentenderse de la imposibilidad jurídica que se advierte en asimilar la contravención administrativa a una falta penal -única manera de concluir en un plazo de prescripción de seis meses para la respectiva acción persecutoria- la que surge de la naturaleza intrínseca del castigo [...]Desde luego, por cuanto la sanción penal presenta características ineludibles, suficientemente estudiadas por la doctrina, como son las de su moralidad, esto es, su fundamento ético; su aflictividad, destinada al restablecimiento del equilibrio social perturbado; su proporcionalidad a la naturaleza de la ilicitud penal de que se trate; su personalidad o individualidad; su igualdad, esto es, una misma conducta debe tener una idéntica sanción; su ejemplaridad, es decir, su potencialidad de intimidación; su publicidad, no solo respecto del castigo sino del justo proceso que a ella condujo; su certeza e ineludibilidad; su prontitud, en relación a su comisión; su revocabilidad para remediar una eventual injusticia; su temporalidad y divisibilidad, para amoldarse a las características del hechor, todas condiciones no necesariamente presentes en la sanción administrativa, pero sí, aplicables a crímenes, simples delitos y faltas [...]"54.

A este respecto, se debe tener presente que la Corte Suprema en esta sentencia no abdica de la tesis de identidad ontológica y del ius puniendi único del Estado. Al respecto, en este fallo la Corte desarrolla toda su argumentación con el objeto de justificar un matiz muy importante res-

53 Corte Suprema. 15 de octubre de 2009. Rol No5.702-2009. "Empresa eléctrica de Aysén S.A. (Edelaysen) contra Dirección Regional de la Superintendencia de Electricidad y Combustibles (sec)". En el mismo sentido, el voto de minoría de la Sentencia de 10 de septiembre de 2009, causa Rol No3357-09. En ambos fallos se mencionan las siguientes sentencias: "Alessandri R. Arturo" (27 de diciembre de 1965). Revista de Derecho y Jurisprudencia. Tomo 62, (1965) segunda parte, sección tercera (páginas 114-119); "Yarur A. Daniel" (31 de marzo de 1966); misma Revista. Tomo 63 (1966), segunda parte, sección primera, (páginas 94-110); "Valdés Freire, Luis" (5 de julio de 1966); misma Revista. Tomo 63 (1966), segunda parte, sección tercera, páginas 88-91; "Banco de Crédito e Inversiones” (12 de julio de 1966); misma Revista. Tomo 63 (1966), segunda parte, sección tercera, páginas 93-95, "Bolumburu Pin. Ezequiel” (13 de agosto de 1966); misma Revista. Tomo 63 (1966), segunda parte, sección tercera, páginas 105-109; "Compañía Telefónica Manquehue”, misma Revista. Tomo 88 (1991), segunda parte, sección quinta, páginas 47-49; y en "Brahm Yuraszeck", misma Revista. Tomo 88 (1991), segunda parte, sección quinta, páginas 33-41.

54 Corte Suprema. 10 de septiembre de 2009. Rol No3357-09, considerandos 8o y 9o. 
pecto de la proyección de los principios del orden penal al ámbito de las sanciones administrativas, relacionado con el plazo de prescripción. Sin embargo, no se discute la tesis predominante en sus sentencias, así como ocurre en la jurisprudencia constitucional y administrativa.

Por lo tanto, la Corte Suprema comparte la doctrina que ha sostenido la jurisprudencia constitucional y administrativa sobre la materia, pero considera los aspectos sustantivos que separan a las delitos de las infracciones administrativas, para matizar en la proyección de los principios y normas del orden penal al ámbito de las sanciones administrativas.

\section{4) CONCLUSiones}

El concepto y naturaleza de las infracciones y sanciones administrativas constituye un presupuesto necesario para poder analizar su régimen jurídico y, particularmente, las bases constitucionales y principios a las cuales debe someterse. En este sentido, resulta fundamental establecer cuál es el concepto y qué naturaleza le han atribuido los principales operadores jurídicos al ejercicio de la potestad punitiva de la Administración. Así, de este estudio es posible arribar a las siguientes conclusiones:

1. La doctrina y jurisprudencia nacional han recibido una clara influencia de la doctrina y jurisprudencia comparada, particularmente aquella que se ha forjado en el Derecho español y que hace una identificación ontológica entre las sanciones penales y las administrativas bajo el concepto de un ius puniendi único del Estado, que se bifurca en estas dos manifestaciones. De esta forma, se asimilan delitos e infracciones administrativas por una parte, y las penas y sanciones administrativas por otra, con el objeto de proyectar los principios del orden penal a estas últimas.

2. Si bien esta doctrina sigue siendo mayoritaria en España, en las dos últimas décadas se ha abierto una tendencia a independizar al Derecho administrativo sancionador del Derecho penal, fundado en principios y categorías propias. Esta tendencia no ha llegado a la jurisprudencia y ha sido recogida parcialmente por la doctrina nacional.

3. Para la doctrina comparada resulta muy relevante distinguir la sanción administrativa respecto de otras actuaciones formales de la Administración que producen efectos desfavorables, especialmente para determinar el régimen jurídico aplicable, en particular los principios y garantías propias al ejercicio del poder punitivo de la Administración. Sin embargo, este análisis prácticamente no ha sido realizado por nuestra doctrina, salvo contadas excepciones, y tampoco ha sido objeto de atención por parte de la jurisprudencia constitucional, administrativa y judicial. 
4. La jurisprudencia constitucional sigue un concepto amplio de sanción administrativa, comprensivo de los actos administrativos de efectos desfavorables, en el marco de los principios y garantías del racional y justo procedimiento administrativo (artículo 19 No 3). Sin embargo, en relación con los principios sustantivos que rigen la potestad sancionadora de la Administración (legalidad, tipicidad, culpabilidad, responsabilidad personal, etc.), se ha centrado fundamentalmente en las sanciones administrativas stricto sensu. Por su parte, la jurisprudencia administrativa también ha seguido un concepto amplio de sanción administrativa, aunque esto no la ha llevado a pronunciamientos relevantes que proyecten los principios de la potestad sancionatoria de la Administración a los actos de efectos desfavorables. Por último, la Corte Suprema ha seguido el concepto estricto de sanción administrativa, centrando su análisis en la finalidad preventiva y represora de estas medidas.

5. La antigua discusión que separa las sanciones penales de las sanciones administrativas, como consecuencia de determinadas conductas calificadas de ilícitas (delitos e infracciones administrativas), ha encontrado un mayor eco en la doctrina penal, la cual sigue la discusión que se ha producido en la doctrina comparada. En este punto resulta determinante la interpretación del artículo 20 del Código Penal, para establecer que en nuestro ordenamiento jurídico subyace un concepto amplio de pena, comprensivo de las penas penales y administrativas. Además, esto permite dar una interpretación amplia de las normas constitucionales sobre la materia (artículo 19 Const.) y proyectar las garantías del orden penal al ámbito administrativo.

6. Tanto la jurisprudencia constitucional, administrativa y judicial siguen la tesis de la identidad ontológica entre sanciones penales y administrativas, bajo la idea de un concepto metanormativo de un único poder punitivo del Estado. A su vez, se reconoce implícitamente que dentro de este marco, corresponde al legislador valorar desde un punto de vista ético-social las conductas punibles y determinar la conveniencia que estas sean aplicadas por la autoridad judicial o administrativa. Sin embargo, nuestro Tribunal Constitucional ha sido claro en sostener que las penas privativas de libertad y las medidas de apremio que la afecten, solo se pueden ordenar por la autoridad judicial. Además, en esta función el legislador debe ponderar, sobre la base del principio de proporcionalidad, los medios utilizados en relación con los fines constitucionales que se pretenden alcanzar y la intensidad de la afección de los derechos fundamentales.

7. En definitiva, para nuestra doctrina y jurisprudencia, las infracciones y sanciones administrativas participan de la misma naturaleza de los delitos y las penas, pues integran un mecanismo de intervención en 
el marco de una política represiva que debe determinar el legislador, sujeto a elementos de proporcionalidad y garantías que son de mayor intensidad considerando la gravedad de la sanción que se va aplicar.

\section{5) Bibliografía}

- Aguerrea, Pedro (2005). "Límites procesales a las potestades sancionadoras de la Administración en la jurisprudencia del Tribunal Constitucional". En AA. VV. Sanciones Administrativas y Derechos fundamentales: regulación y nuevo intervencionismo. Santiago de Chile: Universidad Santo Tomás.

- Alcalde Rodríguez, Enrique (2009). "Algunas consideraciones en torno a la identidad sustancial entre la sanción penal y la pena administrativa”. En Arancibia Mattar, Jaime y Martínez Estay, José Ignacio (coordinadores): La primacía de la persona. Estudios en homenaje al profesor Eduardo Soto Kloss. Santiago de Chile: Legal Publishing, pp. 795-808.

- Aróstica, Iván (1987). "Algunos problemas del Derecho Administrativo Penal". Revista de Derecho Universidad de Concepción, No 182, pp. 71-81.

- Bermúdez, Jorge (1998). "Elementos para definir las sanciones administrativas". Revista Chilena de Derecho, Número Especial, pp. 323-334.

- Bordali, Andrés y Ferrada, Juan Carlos (2008) Estudios de Justicia Administrativa. Santiago de Chile: LexisNexis.

- Camacho Cepeda, Gladys (2010) Tratado de Derecho Administrativo. La actividad sustancial de la Administración del Estado. Santiago de Chile: Abeledo Perrot.

- Cousiño Mac Iver, Luis (1975) Derecho penal chileno. Parte general. Santiago de Chile: Editorial Jurídica de Chile.

- Cury, Enrique (2005) Derecho Penal. Parte General. 8a edición. Santiago de Chile: Universidad Católica de Chile.

- Etcheberry Orthústegui, Alfredo (1998) Derecho penal, $3^{\text {a }}$ edición. T. II. Santiago de Chile: Editorial Jurídica de Chile.

- García de Enterría, Eduardo y Fernández, Tomás-Ramón (1999) Curso de Derecho Administratrivo. T. II, 11 a edición. Madrid: Thomson.

- Garrido Falla, Fernando (2002) Tratado de Derecho Administrativo, $11^{\text {a }}$ edición. Vol. II. Madrid: Tecnos.

- Girola, C. (1929). "Sanzioni penali e sanzioni amministrative". Rivista di Diritto Pubblico I, pp. 429 y ss.

- Goldschmidt, James (1969) Das Verwaltungsstrafrecht. Eine Untersuchung der Grenzgebiete zwischen Strafrecht und 
Verwaltungsrecht auf rechtsgeschichtlicher und rechtsvergleichender Grundlage. Aalen: Scientia Verlag, 603 pp.

- Goldschmidt, James (2010). "Concepto y cometido del Derecho penal administrativo". En Goldschmidt, James: Derecho, derecho penal y proceso. T. I. Problemas fundamentales del Derecho. Madrid: Marcial Pons.

- Merkl, Adolf (2004) Teoría general del Derecho Administrativo, traducción de su obra Allgemeines Verwaltungsrecht, Wien \& Berlin: Springer, 1927. Granada: Comares.

- Novoa Monreal, Eduardo (1985) Curso de Derecho penal chileno. 2a edición. Santiago de Chile: Ediar-ConoSur.

- Ranelletti, O. (1904). "La polizia di sicurezza". En Orlando, V. E. (director): Primo trattato completo di diritto amministrativo italiano. Milano: Libraria.

- Rebollo Puig, Manuel y otros (2010) Derecho Administrativo Sancionador. Madrid: Lex Nova.

- Rodríguez, Luis (1987). "Bases para distinguir entre infracciones criminales y administrativas". Revista de Derecho de la Pontificia Universidad Católica de Valparaíso, XI, pp. 117-163.

- Román Cordero, Cristian (2008). "Derecho Administrativo Sancionador: ¿Ser o no ser? He aquí el dilema”. En Pantoja, Rolando (coordinador): Derecho Administrativo. 120 años de Cátedra. Santiago de Chile: Editorial Jurídica de Chile, pp. 107-141.

- Santamaría Pastor, Juan Alfonso (2009) Principios de Derecho Administrativo. T. II, 2a edición. Madrid: Iustel.

- Sото Kloss, Eduardo (1979/1980). "Derecho Administrativo Penal. Notas para el estudio de la potestad sancionadora de la Administración". Boletín de Investigaciones Facultad de Derecho de la Pontificia Universidad Católica de Chile, No 44-45, pp. 95-103.

- Soto Kloss, Eduardo (2005). "La potestad sancionadora de la Administración, ¿se adecua a la Constitución?”. En AA.VV. Sanciones Administrativas y Derechos fundamentales: regulación y nuevo intervencionismo. Santiago de Chile: Universidad Santo Tomás, pp. 29-49.

- Vergara, Alejandro (2004). "Esquema de los principios del Derecho Administrativo Sancionador". Revista de Derecho Universidad Católica del Norte, año 11, № 2, pp. 137-147.

- Zanobini, Guido (1924) Le sanzioni amministrative. Roma: Bocca. 